\title{
Language analysis -A Case Study-
}

\section{Análisis del lenguaje -un estudio de caso-}

Evelyn Almeida

Universidad Central del Ecuador, Ecuador

Universidad de las Fuerzas Armadas ESPE, Ecuador

Andrea Rosero

Universidad Central del Ecuador, Ecuador

Autor por Correspondencia: evalmeida@uce.edu.ec, aarosero@uce.edu.ec

Fecha de recepción: 24 de Marzo de 2017 - Fecha de aceptación: 5 de Junio de 2017

\section{Resumen}

El objetivo de este estudio fue analizar el desarrollo de una segunda lengua en un adulto. Pedro quién fue el sujeto de este estudio es usuario de A1 de acuerdo con el Marco Común Europeo de Referencia, lo que significa que puede hacer una introducción y utilizar expresiones básicas de saludos. El análisis se basó en una entrevista donde los investigadores centraron su atención en aspectos relacionados con la fonología, la morfosintaxis, el vocabulario y la pragmática, así como también el cambio de código y otras anomalías. Los resultados mostraron que en la manera de dialogar del participante hay teorías, métodos y conceptos que se presentan implícita o explícitamente. También se descubrió que nuestro participante tenía muchos errores de interferencia en el primer idioma, como se explica a lo largo del análisis.

Palabras clave: análisis del lenguaje; teoría socio-cultural; adquisición del idioma

\begin{abstract}
The aim of this study was to analyze, the development of a second language adult learner. Pedro who was the subject of this study is A1 user according to the Common European Framework of Reference, it means that he can make an introduction and use basic greeting and leave-taking expressions. The analysis was based on an interview where the researchers focused their attention on aspects related to phonology, morphosyntax, vocabulary and pragmatics, code switching, and other anomalies. The results showed that in the participant's speaking there are theories, methods, and concepts that are presented implicitly or explicitly. It was also found out that our participant Pedro had many first language interference errors as they were explained along the analysis.
\end{abstract}

Key words: language analysis; socio-cultural theory; language acquisition 


\section{Background Information}

\section{Introduction}

The researchers chose to conduct their language analysis based on a Spanish native speaker from a country in South America, who is forty-two years old and from now on will be called Pedro ${ }^{1}$. He lives with his little 6-month old baby girl and his wife. He arrived to the United States eight months ago. He spends the majority of his time at home taking care of his baby. He took a 30-hour ESL course at a language institute, which from now on will be called NMLI. Additionally he has just completed 50-hours of ESL instruction in an ESL Summer Institute. When the family is at home, they speak Spanish all the time because Spanish is their first language. Husband and wife feel more comfortable speaking in Spanish rather than in English. He speaks English when he goes to buy something in the supermarket or mall and when people in those places do not speak Spanish. It is a fact that, in this city, many people speak Spanish; therefore, it has been hard for Pedro to practice English. This situation brings Vygotsky 's (1978) argument to mind that "language develops primary from social interaction." He goes on to argue "that in a supportive interactive environment, children are able to advance to higher levels of knowledge and performance" (as cited in Lightbown \& Spada, 2013, p. 37).

Pedro finished high school and studied two years of architecture at a university in the city where he is from. During his high school and university years, he studied English as a foreign language. He remembers his English classes as monotonous and given in Spanish. His classes followed a behavioristic theory as he explained. Teachers focused their teaching on imitation, practice, memorization, and habit formation. From what Pedro remembers, English was taught using three main approaches: Total Physical Response (TPR), Grammar Translation, and Audiolingual Method. According to Ellis and Shintani (2013), "Grammar Translation Method is a traditional language approach involving the presentation of grammatical rules, the study of list of vocabulary, and translation exercises. It emphasizes reading rather than the ability to communicate in a language" (p. 338). Pedro mentioned that when he studied in high school, he experienced all these activities in his daily classes. He also remembers using dialogues and drills to practice English, this being a characteristic of Audiolingual Method. According to Ellis and Shintani (2013), Total Physical Response "involves the teacher giving commands and the students responding by performing actions. It is based on a structural syllabus as the commands are designed to expose learners to different grammatical structures" (p. 345).

He learned basic vocabulary and simple structures only. He thinks that the things he learned back in his home country were not enough to be fluent in English. He feels that he needs to practice speaking and to be involved in conversations where English is spoken because he does not speak English at home neither with his child nor with his wife. Pedro needs to meet his zone of proximal development (ZPD) described by Vygotsky (1978) as a "metaphorical place in which children could do more than they would be capable of doing independently" (as cited in Lightbown \& Spada, 2013, p. 37). By using English in conversations, Pedro will be provided with scaffolding to support and develop a higher level of understanding of the English language.

Pedro is A1 user of English according to the levels of the Common European Framework of Reference CEFR (2001). Pedro can make an introduction and use basic greeting and leave-

\footnotetext{
${ }^{1}$ The names of the participants and places were changed to keep their privacy
} 
taking expressions. He can understand sentences and frequently used expressions related to very basic personal and family information. He also manages to communicate in simple and routine tasks requiring a simple and direct exchange of information on familiar and routine matters. He can describe in simple terms aspects of his background. In relation with his speaking ability, he can interact in a simple and direct ways. He can exchange information with difficulty where he has to repeat or rephrase things and he speaks at a slow rate with some accuracy. He can also ask and answer simple questions and initiate and respond to simple statements in areas of immediate need or on very familiar topics. Pedro can ask and answer questions about himself and other people, where he lives, people he knows, things he has, and he can indicate time. Pedro struggles the most with the speaking and the researchers found two major weaknesses: fluency and accuracy.

In order to describe Pedro's characteristics as a second language learner as well as his learning conditions, the researchers have adapted the chart presented by Lightbown and Spada (pg. 37).

\section{Learner Characteristics and Learning Conditions}

\section{Learner Characteristics}

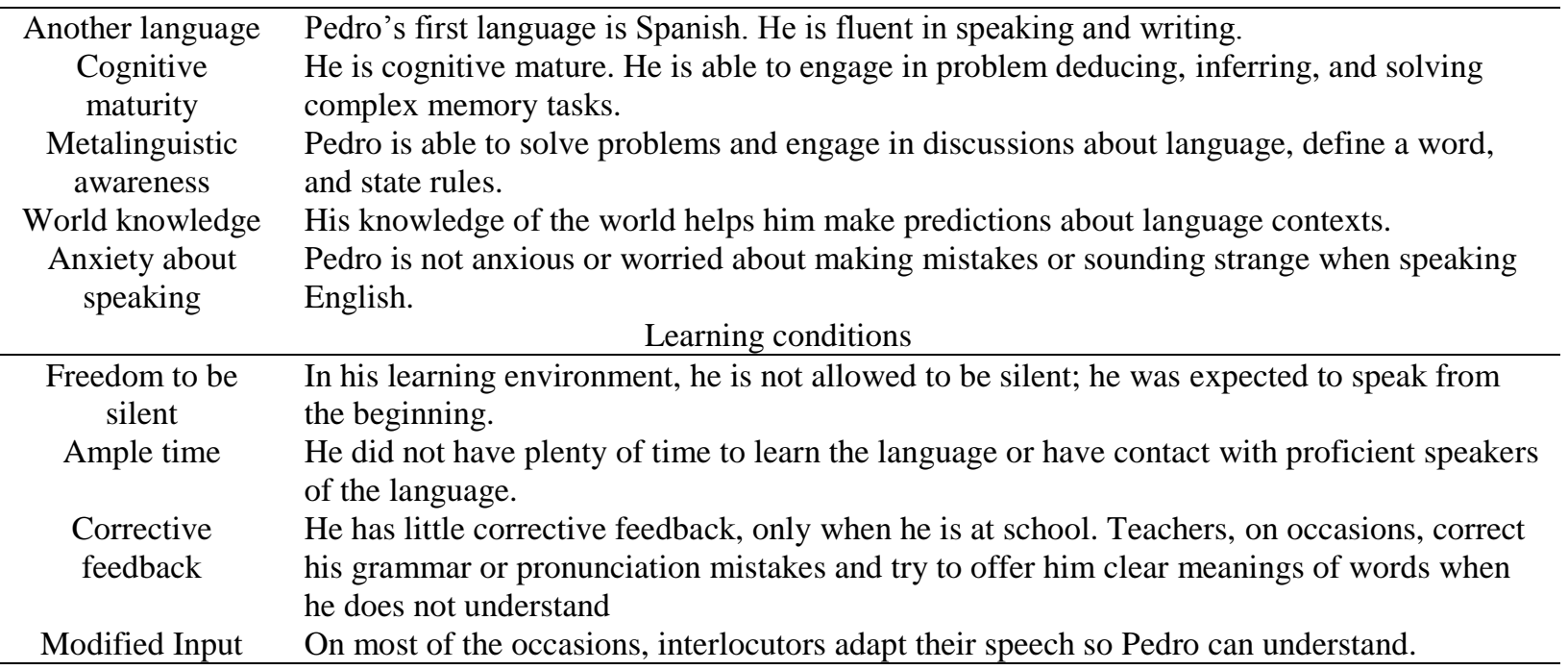

After offering some background information about Pedro, the researchers are going to present the transcription of the interview. The interview took around one hour, but for the purpose of the language analysis, just a portion of it will be used.

\section{Transcription}

Date: Saturday, July $16^{\text {th }}$

Time: 10:00 p.m.

Participants: $\quad[\mathrm{PJ}]=\mathrm{L} 1$ English Learner, Pedro $(42 ; 07)$

$[\mathrm{R}]=$ Researcher

$[\mathrm{A}]=$ Ana, his young daughter

NOTE: Ana is present but did not speak during this language sample. She is 6 months. 
Setting: $\quad$ Pedro, Ana, and a researcher were sitting on the floor in front of the TV. The TV was on in a Spanish soap opera but, at the moment of the interview the TV is muted. Pedro is holding Ana. She is on his lap. She is playing with some toy blocks.

Duration: 3 minutes 17 seconds for the following language sample.

Key:

\begin{tabular}{|c|c|}
\hline / / & $\begin{array}{l}\text { IPA translation for Pedro } \\
\text { Questions from the interviewer }\end{array}$ \\
\hline \multicolumn{2}{|c|}{ (Italicized text) Non-verbal actions } \\
\hline$[!]$ & Filler sound \\
\hline CAPITALS & Ana's interruptions \\
\hline XXX & Unintelligible \\
\hline [Italic text] & English equivalent \\
\hline$[\ldots]$ & Pause longer than 3 seconds \\
\hline [.] & Pause shorter than 3 seconds \\
\hline
\end{tabular}

1. [R]: How old are you?

2. [P]: I /an/ $[a m] 42$ years old.

3. [R]: Pedro please tell me why you are here.

4. [P]: [! ] I/an/ [am] here for my wife and family (Pedro smiles)

5. [R]: Ok. How long have you been here in Washington?

6. [P]: [! ] I/an/ [am] /seben/ [seven] /monds/ [months]

7. [R]: Do you like it here?

8. [P]: I like here. I like Seeatle, Washington, and /steids/ [states] New York,

9. Los Angeles, Hollywood, yeah. (Pedro is playing with Ana)

10. [R]: What did you use to do back in your country?

11. [P]: [!] maybe. Two years. (Pedro has a questioning face)

12. [R]: Ok but what did you use to do when you were in your country?

13. [P]: [...] [ ! ] yo [...] I I when I when do return my country [ ! ] [ ! ] working

14. [R]: Ok Before you came to the United States what did you use to do in

15. Your country?

16. [P]: [ ! ] in my country. I [...] I/an/ [am] /mjusik/ [music] and /sond/ [sound] tech

17. (Pedro nods his head)

18. [R]: Ok. What are you planning to do when you return?

19. [J]: [! ] we return my countryr [!] [!] working with my wife in the city, my country

20. [R]: Ok. Please tell me a little bit about your English learning experiences.

21. When did you learn English?

22. [P]: [! ] learn English in NMLI and course in the /eskul/ [school]. I need learn

23. to much

24. [R]: Would you like to continue studying English?

25. [P]: [ ! ] yeah in NMLI (Pedro nods his head)

26. [R]: Ok. Why do you think it is important to learn English?

27. [P]: Yeah. Is. is important for my life [!] for my profession and business.

28. Ana Is Bothering Pedro. She Is Touching His Face

29. [R]: Why do you say that?

30. [P]: [ ! ] No no [...] what? (Pedro has a questioning face) 


\title{
31. [R]: Why do you say it is important for you? For your
}

32. [P]: [ ! ] I make guitar (stress) and people like my guitars [ ! ] [ ! ] XXX people is ex

33. /ekstrayxeros/ extranjeros (Spanish) (Pedro moves his hands asking for help)

34. [R]: Foreign. Ok is necessary English ANA STARS CRYING

35. ANA KEEPS CRYING (Pedro is trying to calm her down)

36. $[\ldots]$

37. [R]: So Please Pedro tell me what you like to do in Seeatle and what you

38. don't like?

39. [P]: I like in Seeatle [ ! ] I /ka:r/ [care] my baby my family. I learn cooking

40. cook. I don't know /de/ [the] weather /hat/ [hot] weather uffff /hat/ [hot] /hat/ [hot]

41. /hat/[hot] very /hat/ [hot] I don't know.

\begin{abstract}
Analysis
Before conducting the analysis, it is important to emphasis that the cognitive development of a second language adult learner is more stable than a first language learner. Additionally, the experiences and previous knowledge of a second language learner with the language being learned is different not only with a first language learner but also with other second language learners. As Lightbown and Spada (2013) mentioned, "Although the learner's first language does have an influence, many aspects of these developmental stages are similar among learners from different first language backgrounds" (p.45). In this language analysis, the researchers are going to focus on aspects of phonology, morphosyntax, vocabulary and pragmatics, code switching, and other anomalies.
\end{abstract}

Phonology. The researchers will start by analyzing the phonological differences presented in the interview. These differences seen to be a cross-linguistic influence, which, according to Lightbown and Spada (2013), is "the effect on knowledge of one language by the knowledge of another. It also refers to interference to indicate that knowledge of one language can be beneficial to learning another." (p. 216). However, there is also negative interference that can lead to mispronunciation and therefore misunderstanding of the target language.

Vowels. As mentioned by Swan and Smith (2001), Spanish has only five vowels in contrast with English. Therefore, Spanish speakers find it difficult to pronounce all the different vowels sounds in English. For instance, /i:/ and /I/, in Spanish are pronounced as /i/. When Pedro talks about "music" in line 16, he pronounces /mjusik/ instead of /mjuzık/. Another example is $/ æ /, / a: /$, or $/ \Lambda /$ are pronounced /a/ in Spanish. For example, the "to be" verb "am" /æm/ in lines $2,4,6$, and 16 is pronounced /an/. Another example is the word "months" in line 6 . The same thing happens in line 6 when Pedro talks about the amount of time he has been in the United States; Pedro pronounces "seven" as /seben/ instead of /sevən/.

There is also another confusion as mentioned by Swan and Smith (2001) with the vowel sound "/o:/ and /p/ which correspond to Spanish/Catalan/o/" (p. 91). This is seen when Pedro uses the word "for" in line 25. The English pronunciation would be /for/ but because in Spanish we do not have that sound, "for" is pronounced/for/. Another example is the word "hot" in lines 40 and 41 which Pedro pronounces $/ \mathrm{hat} / \mathrm{not} / \mathrm{hpt} /$. Pedro also confuses the sound of $/ \mathrm{\Lambda} /$ for $/ \mathrm{o} / \mathrm{in}$ line 6 when he pronounces "months" as /monds/ instead of $/ \mathrm{m} \Lambda \mathrm{n} \theta \mathrm{s} /$. 
Consonants. Swan and Smith (2001) state, "In Spanish, $/ \mathrm{n} /$ or $/ \mathrm{y} /$ tends to replace $/ \mathrm{m} / \mathrm{in}$ the final position" (p.92). This is because we do not have words that end in $/ \mathrm{m} /$. An example of this is seen in lines 2, 4, and 6. Pedro meant to say "I am" / I æm/ and he said /an/ because of the little practice of pronouncing words that end in "m." Razfar and Rumenapp (2014) say, "A Spanish speaker may have difficulty hearing the difference between /b/ and /v/ because in Spanish these are not two different phonemes" (p. 51). Additionally, Swan and Smith (2001) also stated, "Spanish, and most varieties of Catalan, only have one sound in the area of /b/ and /v/ (pronounced intervocally as a bilabial fricative or continuant); hence confusion between pairs like bowels and vowels" (p. 93). In the interview, there is an example of this confusion in pronunciation. In line 6, Pedro talks about how many months he has been in the United States. Pedro pronounced /seben/ instead of /sevən/, changing /v/ for /b/.

Another distinction is the use of /d/ instead of /ð/. This situation is very common in Spanish speakers because the pronunciation of /ð/ and $/ \theta /$ do not exist in Spanish. Lightbown and Spada (2013) suggests that "Few languages have the "th" sounds that are frequent in English, and learners may substitute similar sounds from their first language (for example, "r" or "d", "s" or "z")" (p. 68). Pedro uses this variation in his speech. In line 40, Pedro talks about "the weather" she pronounces /de/ and not /ðə/. In line 6 the word "months" is pronounces /monds/, leaving the $/ \theta /$ sound unpronounced. There is also another anomaly related to voicing, especially with the contrast between the sounds /s/ and /z/. The Spanish alphabet has the consonant " $\mathrm{z}$ " but it is usually pronunced as $/ \mathrm{s} /$. Pedro expresses this dichotomy when he says "music" in line 16. He says /mjusik/ using /s/ sound instead of /z/.

Consonant Cluster. Swan and Smith (2001) mention that "/s/ plus another consonant, as in Spain, sceptic, and stop, never occurs at the beginning of the word in Spanish or Catalan, so words such as these are commonly mispronounced as Espain, esceptic, estop" (p. 94). An example of this situation is presented in line 21; Pedro was talking about the school he went during the summer. He mentioned the school. However, instead of saying /Skul/ Pedro pronounced /eskul/.

Morphosyntax. "There is no doubt that learners draw on the patterns of other languages they know as they try to discover the complexities of the new languages they are learning" (Lightbown \& Spada, 2013, p.57). A situation commonly seen in the transcription is the omission of personal pronouns in some of the sentences. Swan and Smith (2001) state that "subject personal pronouns are largely unnecessary in Spanish/Catalan because the verb ending indicates person and number: Rosa isn't French. Is Spanish" (p. 105). This phenomenon can be seen in line 22 "learn English in NMLI" and in line 27 "is important." Pedro omits the personal pronouns "I" and "It" respectively.

Pedro also omitted infinitives. Pedro says "I need learn" instead of saying "I need to learn" in line 22. This is because "Spanish and Catalan have an infinitive marker, but its distribution does not square fully with English" (Swan \& Smith, 2001, p.104). Pedro also uses the preposition of place "in" for all cases. In English there are in, on, and, at. In lines 22 and 25 he says "in NMLI" instead of saying "at NMLI." This is because in Spanish, there is only "en" and its direct translation is "in". 
In regards to the grammatical morpheme acquisition, Pedro tends to use more present progressive "ing" in his sentences because this is the first sequence second language learners learn. Krashen (1982) would argue that Pedro's acquisition sequence is part of the natural order of acquisition common to learners of English as a second language (ESL) regardless of the impact of variables such as age and L1 background. An example is when Pedro uses the progressive "ing" structure in lines 13 and 19 where he uses "working" and in line 39 "cooking". According to Lightbown and Spada (2013), Pedro fluctuates between stage 2 and 3 of acquisiton of negative sentences. Pedro uses "no" "no" in line 30 and "I don't know" in lines 40 and 41 . He uses correctly the auxiliary "don't," however, what he meant to say from the dialogue was "I don't like." It may be a confusion or that he did not fully analyze the structure.

Regarding the acquisition of questions and from the information obtained from a single sample, it might seem that Pedro is in stage 1 using a single word "what" in line 30 . However, because of his comprehension of the questions and his answers, Pedro seems to be in stage 3 . He understands questions with the auxiliary "do" and "wh" questions. This fluctuation might be related to the lack of opportunities to practice English. Pedro knows when to use wh-questions and the auxiliaries "do," "does," and "did" and their negatives. It seems that this information is in his repertoire, but he does not always use them in his conversations.

Pedro also has a confusion with subject verb agreement. In line 32 He says, "people is" instead of saying "people are." This is because in Spanish "people" is a singular noun, as in "la gente es." Other anomalies the researchers found in Pedro's speech are the use of the auxiliary "do" in affirmative sentence, repetitions, and using simple present tense to talk about the future. These features are seen in only one sentence, "I when I when do return my country [ ! ] [ ! ] working" in line 13. Swan and Smith (2001) affirm my hypothesis when they say that "the simple present is often used to refer to future time" (p.102)

Vocabulary and Pragmatics. According to the vocabulary Pedro used in the interview, it shows that he uses single- syllable words such as like, hot, life, which are one-syllable words that refer to easy illustrated actions and objects. These are the types of words that word-learners might already know, as Lightbown and Spada (2013) mention, "because they are part of an international vocabulary" (p.63). Other examples are the words from Seeatle, Ecuador, New York, Los Angeles, and Hollywood and the places Pedro had been.

Pedro had also problems using phrasal verbs such as "take care" in line 39. Here, Pedro just says "care." This is because Spanish does not have phrasal verbs. Swan and Smith (2001) also corroborate with this idea when they mention that there is a "problem with two- and threepart verbs, in many cases because the meaning of the English compound is not deducible from the meaning of the parts, and because learners feel more comfortable with a synonym derived from Latin" (p.101).

Pedro managed to use some complicated three-syllable vocabulary such as, "important" in line 27, "profession" in line 27, and "family" in lines 4 and 39 because they are cognates, which mean "words in one language that comes from the same origin as a word in another language and has the same meaning" (Lightbown and Spada, 2013, p. 214). This concept also 
can explain why Pedro could not say the word "extranjeros" in English, "extranjeros" and "foreigners" are not cognates.

Focusing on the pragmatics, Pedro seems to be in stage 3, "Unpacking," according to Kasper and Rose (2002) mentioned in Lightbown and Spada (2013). Pedro uses formulas incorporated into productive language use, he uses more productive speech, and he can follow the conversation except when there are long complex questions such as "What did you use to do back in your country?" in line 10 or "Before you came to the United States what did you use to do in your country?" in line 14.

Additionally, during the interview Pedro used many gap filler sounds. He used gap fillers especially at the beginning of his sentences such as in lines 4, 6, 11, 13, 16, 19, 22, 25, 30, and 32. He used these gap fillers as a strategy to have time and to think about the possible answers for the questions the researcher was asking him. The gap fillers that Pedro used in his interview did not have meaning. He used sound expressions such as, $u h / \Lambda /$, er /3:/, and $u m / \Lambda \mathrm{m} /$.

Code switching. There are different definitions and interpretations for code-switching. Paradis (2012) mentions that code-switching "involves the use of actual words or phrases from one language in a sentence or stretches of discourse in the other language" (p.82). On the other hand, Paradis, Genesee, and Crago (2011) talk about code-mixing and define it as "the use of elements from two languages in the same utterance or in the same stretch of conversation" (p.88). They also talk about intra-utterance code-mixing, when the elements occur in the same utterance, and inter-utterance code-mixing, when they occur in two different utterances.

In the sample provided, Pedro has used "intrasentential" code-switching, which "can consist of mixing a single content word or phrase into a sentence in the other language, switching between clauses in complex sentences, or using multiple switch points within one sentence" (Paradis, 2011, p.81). In lines 13 and 33, Pedro uses single words in Spanish "yo" and "extranjeros." According to Lightbown and Spada (2013), there are two different purposes for it. In line 13, Pedro uses "yo" as the most frequently used word. The other one is in line 33, he uses the word "extranjeros" in Spanish because it reflects the absence of that particular vocabulary word in English. This situation can also be related to the Lexical Gap Hypothesis presented by Paradis et al. (2012), where "children and adults mix words from one language into an utterance in another language when they do not know or cannot easily access the word in the appropriate language" (p.268).

Other errors. There are some errors that the researchers consider neither first language interference nor part of the normal second language development. Because of this reason, we created another category for Pedro's individual errors. Ellis and Shintani (2013) cited Dulay and Burt (1960b) who back up this hypothesis when they classified second language learners' errors in terms of: developmental, interference, and unique. We believe the following errors presented by Pedro are unique because they do not follow the rules of developmental or interference. One example is the word "states" in line 8, Pedro pronounces /steids/ and the word "sound" in line 16 , which is pronounced/sond/. 
Theories, methods, and concepts. There are theories, methods, and concepts that are presented implicitly or explicitly in Pedro's second language learning. The first stage of his learning was in his home country. His learning was characterized by the behaviorist theory, which is a "psychological theory that all learning, whether verbal or non-verbal, takes place through the establishment of habits, when learners imitate and repeat the language they hear in their surrounding environment and are positively reinforced for doing so" (Lightbown \& Spada, 2013, p. 214).

There were three methods that emphasize his English learning in school and university. Grammar Translations, Audiolingual Method, and Total Physical Response. As Ellis and Shintani (2013) state, Grammar Translation Method "is a traditional language approach involving the presentation of grammatical rules, the study of a list of vocabulary, and translation exercises. It emphasizes reading rather than the ability to communicate in a language" (p.338). Lightbown and Spada (2013) also offer a definition for Grammar Translation as "an approach to second language teaching characterized by the explicit teaching of grammar rules and the use of translation exercises"(p.218). This teaching method was used in Pedro's instruction. He used to memorize list of verbs in present, past, and past participle. He was tested on the translation of the verb in Spanish and English. From what he remembered, the teachers used to teach the classes in Spanish and expect their students to speak English, which the researchers personally think does not make sense.

Regarding Audiolingual Method, Ellis and Shintani (2013) define it as a "method of foreign or second language teaching based on behaviorist learning theory. It emphasizes the use of dialogues and drills and avoidance of the use of the L1 to develop correct L2 habits" (p. 344). Pedro was exposed to different activities using Audiolingual Method; he had to repeat many drills and memorize them. The practice that he had was only from lines and dialogues that came from grammar books. Lightbown and Spada (2013) also indicate that this approach is "based on behaviorist theory of learning and on structural linguistics, especially in the contrastive analysis hypothesis. This instructional approach emphasizes the formation of habits through the repetition, practice, and memorization of sentence patterns in isolation" (p. 213). From the dialogues Pedro learned in school, he was not able to carry a simple conversation because the dialogues he had to memorize were out of context and were not meaningful for him; in other words, there was no meaning learning or cognitive process.

Pedro also learned using Total Physical Response, which "involves the teacher giving commands and the students responding by performing actions. It is based on a structural syllabus as the commands are designed to expose learners to different grammatical structures" (Ellis \& Shintani, 2013, p. 345). Pedro remembers that in elementary school his teachers used to teach him using this method. They taught students different commands, which they had to follow such as "sit down," "sand up," "open your book on page," "point to," and "repeat after me."

Pedro thinks that to learn English, the teacher needs to know the students first language. He also considers that grammar translation is essential in specific aspects. He believes that when trying to understand English structures, the teacher should explain in a prescriptive form. The researchers believe these approaches could have helped Pedro if they were used with other methods that helped him also develop his productive skills. What he learned with Grammar 
Translation, Audiolingual Approach, and Total Physical Response was an enormous list of vocabulary and grammar structures that he could not use in context. He learned to pronounce some words and phrases but without knowing the real meaning and how to use them somewhere else.

Norton (2000) cited Canale and Swain (1980) and Canale's (1983) conceptualization of communicative competence in identifying four characteristics: grammatical competence, sociolinguistic competence, discourse competence, and strategic competence. We believe Pedro obtained his grammatical competence in school in his home country. He had the knowledge of the English language code; however, he did not have the ability to produce and understand questions, sentences, or phrases appropriately. He could not master communication strategies and he was not able to "combine grammatical form into large stretches of spoken or written discourse" (Norton, 2000, p.18).

The second part of Pedro's learning, which had been in the United States had been characterized by a more Constructivists Approach, Sociocultural Method, Scaffolding, Zone of Proximal Development, Acculturation method, and Input and Affective Filter Hypothesis. When Pedro came to the United States, he faced language shock; he was frustrated because he could not communicate with people in English. He did not understand the questions people asked him, and he could not explain what he wanted.

Living in an English speaking country and being surrounded by people who speak English, created in Pedro the necessity and motivation to communicate and to socialize with people. Humans are social beings and as Rogoff (2003) mentions "humans develop through changing participation in the socio-cultural activities of their communities, which also change" (p.11). Pedro is developing in a new community where people have other languages, cultures, traditions, and behaviors. The best way to learn a language is when the learner is an active participant of his own learning. This learning should be meaningful and in real contexts. Therefore, Sociocultural Theory best fits the process that Pedro is going through now. This theory states that "higher order language functions are seen as developing both in and out of social interaction. Learners progress functions from object- and other- regulation to selfregulation through interacting with others" (Ellis and Shintani 2013, p. 344).

Lightbown and Spada (2013) back up the hypothesis that Pedro needs to interact with people who speak English in order to be a competent user, they state that Sociocultural Theory is "an expansion for knowledge and learning that is based on the assumption that all learning is first social then individual" (p.223). With this view in mind, Pedro can learn the language and culture through a socially mediated process, with a face to face interaction. Additionally, with this type of interaction, Pedro will encounter his zone of proximal development ZPD described by Vygotsky (1978) as a "the distance between the actual developmental level as determined by independent problem solving and the level of potential development as determined through adult guidance or in collaboration with more capable peers" (as cited in Ellis \& Shintani, 2013, p.346).

By using English in conversations, Pedro will also be provided with scaffolding to support and develop a higher level of understanding of the English language. This scaffolding is an "interactional process where one speaker (an expert or a novice) assists another speaker (a 
novice) to perform skill that the novice is unable to perform independently" (Ellis and Shintani 2013, p. 344). In this case, the experts could be the native speakers in the community or Pedro's teachers from NMLI or the Summer Institute where he studied and will continue studying. The novice could be his classmates or other people from the community. Other important fact is that with scaffolding Pedro will be able to cover all his cultural and linguistic gaps such as vocabulary. As Lightbown and Spada (2013) mentioned, scaffolding is "the language that an interlocutor uses to support the communicative success of another speaker. It may include the provision of missing vocabulary or the expansion of the speaker's incomplete sentence" (p.223).

The Affective Filter is an important hypothesis that describes Pedro's motivation to learn English. One of his biggest motivations to learn English is because he has a rock back in in country. Singing in English and playing his guitar are some of biggest passions in his life. Krashen (1982) presents a definition of Affective Filter Hypothesis, which describes Pedro's motivation for learning English. He mentions that Affective Filter "captures the relationship between affective variables and the process of second language acquisition by positing that acquirers vary with respect to the strength or level of their Affective Filters" (p.30). Something positive about Pedro is that he has motivation to learn English, he is self-confident about his skills in the language, and he is not fearful or anxious about making mistakes in English. As Krashen (1982) mentions that performers with high motivation, with self-confidence generally do better in second language acquisition, and low anxiety appears to be conducive to second language acquisition, whether measured as personal or classroom anxiety.

The last hypothesis that the researchers are going to focus on is Input Hypothesis. Krashen (1982) states that "we acquire by understanding language that contains structure that are a bit beyond our current level of competence. This is done with the help of context or extralinguistic information" (p.21). Pedro has more opportunities to encounter people who speak English in the United States than in his country. He has more input than ever before. The following chart from Krashen (1982) shows the process of language acquisition. We think the graph represents what is happening to Pedro right now. With more input and with his motivation and self-confidence (filter), he will eventually acquire the language.

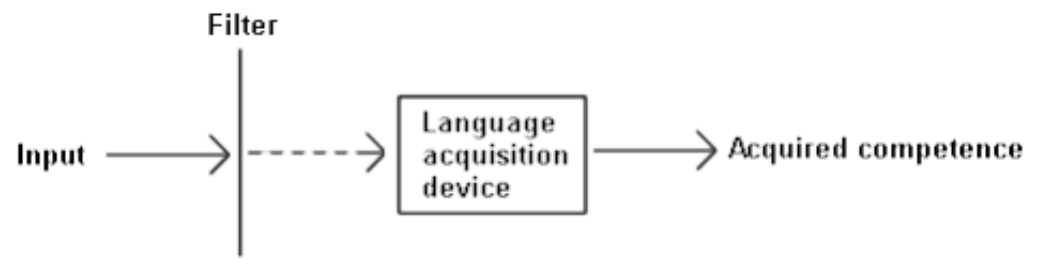

Krashen's (1982) Affective Filter Hypothesis Process p. 32

\section{Disccussion and Conclusion}

There is no doubt that this research has brought up important conclusions for learning. First because the researchers are foreigners. During the analysis, recognizing the phonological features was difficult for us because the same as Pedro, our first language is Spanish. Therefore, identifying phonetic sounds in English, which we do not have in Spanish took a lot of time. We have to say that the materials played an important roles when trying to distinguish patterns, errors, and linguistics features. We also used other books from different subjects to help, especially when they were about second language learners. Something interesting was that, 
because of the researchers' English Teaching background, we tend to look for errors, and this research was not the exception. We were very meticulous about looking for errors and not only the participant, but also ours. We found out that Pedro had many first language interference errors as it was explained in the analysis. However, it was shocking for the researchers to found out that we also had some errors. When listening to the interview, it was heard that in the indirect questions Pedro was asked, we still used auxiliaries. We hope that after listening to these errors, we pay more attention to the correct use of indirect questions.

It was amazing to see how much information you can get from a small sample such as this one. As a student, the researchers changed their perspective and their positionality. We tend to rely on the sociocultural theory and the importance of culture and social factors in the development of language. Additionally, we believe that Behaviorism works more for L1 learners and not much for L2 especially adults. Finally, While doing this, the researchers found out that Pedro helps her little child develop her second language (English) after hearing us talking about the importance and the benefits of being bilingual. They realized that in the mornings when his wife was out, he put cartoons on the TV in English for his little baby to be familiar with the lnaguage. They both wacth "Dinosaur Train," they even sing and dance together.

\section{Bibliography}

Council of Europe. (2001). Common European framework of reference for languages: Learning, teaching, assessment. Cambridge, U.K.: Cambridge University Press.

Ellis, R., \& Shintani, N. (2014). Exploring language pedagogy through second language acquisition research. New York, NY: Routledge.

Krashen, S. D. (1982). Principles and practice in second language acquisition (1st ed.). Oxford: Pergamon.

Lightbown, P. \& Spada, N. (2013). How languages are learned, $4^{\text {th }}$ Ed. UK: Oxford.

Norton, B. (2000). Identity and language learning: Gender, ethnicity and educational change. Harlow, England: Longman.

Paradis, J. (2012). Cross-linguistic influence and code switching. In B. A. E. Goldstein (Ed), Bilingual Language Development and Disorders in Spanish-English Speakers. Second Edition (pp.7391). Baltimore, MD: Brookes Publishing Company.

Paradis, J., Genesee, F., \& Crago, M. (2011). Dual language development \& disorders: A handbook on bilingualism \& second language learning, ( ${ }^{\text {nd }}$ Ed.). Baltimore MD: Paul H. Brookes Publ.

Razfar, A., \& Rumenapp, J. C. (2014). Applying linguistics in the classroom: A sociocultural approach. New York, NY: Routledge.

Rogoff, B. (2003). The cultural nature of human development. Oxford, UK: Oxford University Press.

Swan, M., \& Smith, B. (2001). Learner English: A teacher's guide to interference and other problems $\left(2^{\text {nd }}\right.$ ed.). (Cambridge handbooks for language teachers; Cambridge handbooks for language teachers). Cambridge, U.K.: University Press. 